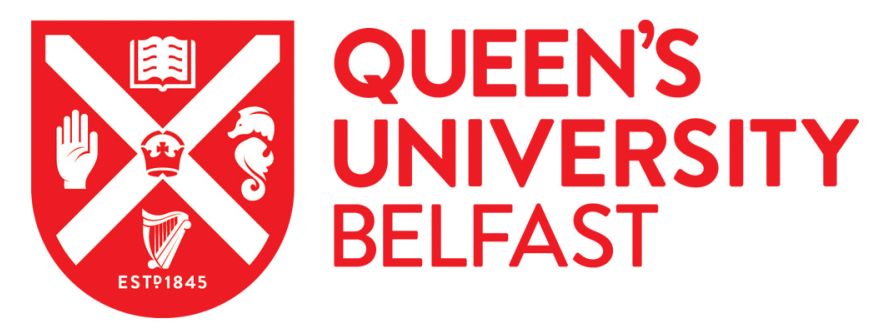

\title{
UK Consensus on Normal Tissue Dose Constraints for Stereotactic Radiotherapy SABR Dose Constraints
}

Hanna, G., Murray, L., Patel, R., Jain, S., Aitken, K., Franks, K., van As, N., Tree, A., Hatfield, P., Harrow, S., McDonald, F., Ahmed, M., Saran, F., Webster, G., Khoo, V., Landau, D., Eaton, D., \& Hawkins, M. (2017). UK Consensus on Normal Tissue Dose Constraints for Stereotactic Radiotherapy SABR Dose Constraints. Clinical Oncology. https://doi.org/10.1016/j.clon.2017.09.007

Published in:

Clinical Oncology

Document Version:

Peer reviewed version

Queen's University Belfast - Research Portal:

Link to publication record in Queen's University Belfast Research Portal

Publisher rights

Copyright 2017 Elsevier.

This manuscript is distributed under a Creative Commons Attribution-NonCommercial-NoDerivs License

(https://creativecommons.org/licenses/by-nc-nd/4.0/), which permits distribution and reproduction for non-commercial purposes, provided the author and source are cited.

\section{General rights}

Copyright for the publications made accessible via the Queen's University Belfast Research Portal is retained by the author(s) and / or other copyright owners and it is a condition of accessing these publications that users recognise and abide by the legal requirements associated with these rights.

Take down policy

The Research Portal is Queen's institutional repository that provides access to Queen's research output. Every effort has been made to ensure that content in the Research Portal does not infringe any person's rights, or applicable UK laws. If you discover content in the Research Portal that you believe breaches copyright or violates any law, please contact openaccess@qub.ac.uk. 


\section{UK Consensus on Normal Tissue Dose Constraints for Stereotactic Radiotherapy}

\section{Authors and Affiliations:}

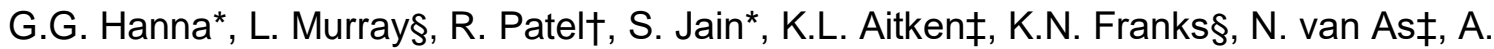

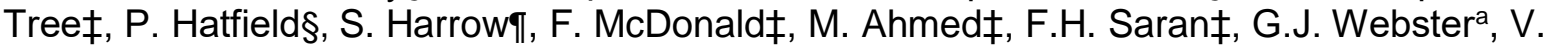
Khooł, D. Landau ${ }^{b}$, D.J. Eaton†, M.A. Hawkins ${ }^{c}$

* Centre for Cancer Research and Cell Biology, Queen's University of Belfast, Belfast, UK $\S$ Department of Clinical Oncology, St James's Institute of Oncology, Leeds Cancer Centre, Leeds, UK

† National Radiotherapy Trials Quality Assurance Group, Mount Vernon Hospital, Northwood, UK $\ddagger$ Department of Radiotherapy, Royal Marsden NHS Foundation Trust \& Institute of Cancer Research, London, UK

I[ Department of Radiotherapy, Beatson West of Scotland Cancer Centre, Glasgow, UK a Department of Radiotherapy, Worcester Oncology Centre, Worcester, UK b Department of Oncology, Guy's and St Thomas' Hospital, London, UK

c CRUK/MRC Oxford Institute for Radiation Oncology, University of Oxford, Oxford, UK

\section{Author notes:}

1.) Both G.G. Hanna and L. Murray Contributed equally to this manuscript.

2.) Both D.J. Eaton and M.A. Hawkins Contributed equally to this manuscript.

\section{Corresponding Author:}

Dr Gerard G. Hanna

Centre for Cancer Research and Cell Biology, Queen's University of Belfast, 95 Lisburn Road, Belfast, UK, BT9 7AE.

Email: g.hanna@qub.ac.uk

Keywords: SABR, SBRT, stereotactic radiotherapy, normal tissue, OAR, constraints.

\section{Conflict of Interest statement:}

See conflict of interest doc

$\begin{array}{ll}\text { Word Count: } & 2996 \text { (excluding references and tables) } \\ \text { Number of tables: } & 4 \\ \text { Number of figures: } & 1\end{array}$




\section{Abstract:}

6 UK studies investigating SABR are currently open. Many of these involve treatment of oligometastatic disease at different locations in the body. Members of all the trial management groups collaborated to generate a consensus document on appropriate organ at risk (OAR) dose constraints. Values from existing but older reviews were updated using data from current studies. It is hoped that this unified approach will facilitate standardised implementation of SABR across the UK and will permit meaningful toxicity comparisons between SABR studies and internationally. 


\section{Manuscript - UK Consensus on Normal Tissue Dose Constraints for Stereotactic Radiotherapy}

\section{Introduction}

Stereotactic ablative radiotherapy (SABR or SBRT) is routinely used for the treatment of early stage peripheral lung cancer and is increasingly used to treat other primary or metastatic tumour sites [1-9]. There are currently a number of UK studies open to recruitment (of which 3 are randomised trials) investigating the utility of SABR in the treatment of oligometastatic disease (breast, lung, and prostate), lung, prostate, pancreas and hepatobiliary primary malignancies[10-13]. These are supported by Cancer Research UK (CRUK) and further studies are in development. In addition, a NHS Commissioning through Evaluation (CtE) programme was commenced in 2015 to evaluate SABR in situations where clinical trials are not available [14].

The focus of many of these studies is the use of SABR in the treatment of oligometastatic disease. Inherent in the delivery of SABR to oligometastatic sites at any location in the body is an understanding of the local normal tissue dose constraints. It is recognised that as SABR is a relatively new treatment technique, definitively established dose constraints which directly correlate to risk of toxicity are rare. However, in order to standardise protocols and the associated radiotherapy planning, members of the various trial management groups collaborated to generate a consensus document on appropriate organ at risk (OAR) dose constraints associated with the various common SABR fractionations.

There are numerous publications which report toxicity following SABR at various sites. These have been summarised in a number of reports or reviews [15-18]. The most comprehensive of these reviews is the AAPM-101 report [16], but this is now over 5 years old, and newer data 
are available. Rather than conduct a primary systemic review, the values contained within the AAPM-101 report were revised where appropriate, by taking into consideration any updated or more robust data on a given dose constraint value in the opinion of the panel, as described below.

\section{General principles of dose constraint selection and application to clinical trials or routine practice}

In choosing the most appropriate dose constraints for UK SABR treatments, the following principles in selecting and applying these dose constraints have been used:

1.) Both optimal and mandatory dose constraints were included, where appropriate;

2.) For body (extra-cranial) dose constraints, except for the spinal cord/canal, a near-point maximum dose volume of $0.5 \mathrm{cc}$ should be used across sites. This represents a volume which is both clinically realistic and comparable when calculated across different planning systems. For cranial regions, and the spinal canal as a surrogate for cord dose in most cases, a nearpoint maximum dose volume of $0.1 \mathrm{cc}$ should be used. It should be noted that where the area to be treated abuts the spinal cord, the spinal cord should be explicitly defined on both CT and MRI, and a margin for set-up errors added based on local specification;

3.) There are differences in the ways dose constraints are reported for serial and parallel organs. Care should be taken to distinguish between these and the key principles are listed in Figure 1. 
4.) For the purpose of these guidelines, single fraction treatment should not be given extracranially. 3 or 5 fraction regimes are recommended, along with 8 fractions for selected thoracic lesions;

5.) Radiation Therapy Oncology Group (RTOG) normal tissue atlases should be used for delineation of OARs [19]. Specifically it is recommended to follow the RTOG guidance by contouring the spinal canal based on the bony limits of the spinal canal. The spinal cord should be contoured starting at the level just below cricoid (or at the level of the base of skull for tumour of the lung apex) and continuing on every CT slice to the bottom of L2. Neural foraminae should not be included;

6.) The dose constraints described in this document are only applicable for patients receiving SABR alone. For patients who have received recent or are receiving concomitant systemic therapy (and in particular anti-angiogenic agents and other biological agents) there may be an enhanced risk of normal tissue toxicity;

7.) These dose constraints are not applicable to re-irradiation of the same organ using SABR, except where another part of the organ (e.g. lung or liver) has incidentally previously received standard fractionation radiotherapy on a previous occasion;

8.) Where 2 separate GTVs are being treated in the same organ (e.g. two separate lung metastases) during the same treatment course, then the summed dose to both lesions and associated OARs should not usually exceed the given dose constraints;

9.) Where patients are having more than one lung lesion treated with SABR, it is recommended that these should be treated on alternate days and with the same dose/fractionation (usually the most conservative schedule). The use of alternate day treatments reduces the dose per fraction to the whole lung, and is recommended in an effort 
to limit the risk of severe pneumonitis and fibrosis. Both sites may be treated on the same day is if the tumours can be encompassed in a single field, for small metastases in otherwise fit patients, or when the combined percentage of lung volume receiving a dose of 20Gy or higher (V20 Gy) is below the tolerance for a single lesion. There is little published data on normal tissue tolerances for multiple lesions and ideally the standard thoracic constraints should be met. However, the OAR constraint which is most likely to be exceeded is the V20 Gy. In the case of treating two or three lung lesions, the following V20 Gy lung constraints should be followed:

\begin{tabular}{ll}
$\circ$ Optimal & $<12.5 \%$ \\
\hline Acceptable in all cases & $<15 \%$ \\
\hline Acceptable in selected cases with good lung function & $<20 \%$
\end{tabular}

Where the lung function parameters of forced expiratory volume in 1 second (FEV1) and transfer factor (DLCO) are below $40 \%$ of predicted, its strongly recommended that the V20 Gy should be kept below 12.5\% (optimal) or 15\% (mandatory).

10.) Where patients are having more than one liver metastasis treated with SABR, it is recommended a 5 fractions regime is used and that all OAR constraints should be met as per single lesion, with at least 40 hours (alternate days) between treatments.

11.) These dose constraints are to be used as guidance only. Those using these dose constraints should note that the final responsibility for radiotherapy plan evaluation remains with the treating clinician and the treating institution. Changes should be justified using good a priori medical reasons. 
12.) These constraints will be reviewed as part of biennial updates to the UK SABR Consortium guidelines.

\section{Specific principles for each anatomical site grouping}

CNS (Table 1) - These constraints are primarily based on those described in the AAPM-101 report[16], with some modification to give consistent near-point maximum dose volumes for serial organs $(0.1 \mathrm{cc})$, and taking account of recent risk analyses for optics and spinal cord $[20,21]$. Cochlea volumes are usually so small than the mean dose may be considered as the near-point dose, and an optimal limit has been added to reflect recent studies [22]. Optimal limits have also been added for lens and orbit (as a surrogate for retina), though these should generally be kept as low as reasonable practicable. Single fraction treatments are recommended for CNS metastases, but multi-fraction constraints are also included for large lesions, or in the rare event of skull bone metastases receiving SABR treatment. These constraints are not specifically designed for stereotactic radiosurgery (SRS), but may be useful in this regard also. However some centres have used higher tolerances successfully, or sought to spare other structures such as trigeminal nerve.

Thoracic (Table 2) - For 3 and 5 fractions schedules, as well as Optimal values for 8 fraction schedules, updated constraints are taken from the UK SABR consortium guidelines [18], which were based on those used in the ROSEL trial [23] and VU Amsterdam practice. For 8 fraction Mandatory constraints, those used in the LungTech trial [24] have been adopted. These, in turn, were based on the treatment strategies for 8 fraction SABR for central lung cancers (i.e. those within $2 \mathrm{~cm}$ of main airways or proximal bronchial tree) as described by Haasbeek et al [25] and shaped by additional information from trials and clinical practice [24,26,27]. The LungTech protocol describes dose constraints for all OARs except the heart and great vessels, 
where UK SABR consortium constraints have been adopted for both Optimal and Mandatory values [18]. When delineating the proximal bronchial tree, defined as the most inferior $2 \mathrm{~cm}$ of distal trachea and the proximal airways on both sides, both mediastinal and lung windows on CT should be used, as appropriate to each case. For "ultra-central" tumours i.e. those adjacent to the hilar structures, with GTV directly abutting a main bronchus [28], there is still uncertainty regarding the OAR tolerances for SABR given concerns about significant toxicity. A recent updated version of the LungTech protocol has allowed higher doses the proximal bronchial tree for those tumours whose PTV is near or abutting the wall of the proximal bronchial tree. In this scenario a subvolume is delineated of the adjacent proximal bronchial tree that is allowed to have 60Gy in 8 fractions. Therefore we would recommend a cautious approach for central and particularly ultra-central tumours and patients should be consented for the potential increased risk of toxicity. Such patients should be treated in a clinical trial or in a prospective evaluation programme.

Gastro-Intestinal and Abdomen (Table 3) - For five fraction schedules, updated constraints are taken from the ABC-07 trial and the SPARC study $[13,29]$. These constraints incorporate revised AAPM-101 constraints in light of published trials data [30-32] and do not apply for cirrhotic liver. For three fraction schedules, constraints are those described by the AAPM-101 report [16], with additional liver constraints from other early SABR work [33-35]. The ABC-07 and SPARC trials do not include a rectal constraint and so both 3 and 5 fraction constraints are those reported by AAPM-101 [16]. For lower lobe lung treatments, significant irradiation of the abdominal structures is not a common clinical occurrence where co-planar delivery is employed. If there is a risk of significant irradiation of an adjacent intra-abdominal organ (e.g. liver for right lower lobe lung tumours), then imaging of the entire organ should occur at simulation.

Pelvis and Other (Table 4) - Updated constraints are available from the PACE trial (5 fractions) [12], however these apply specifically to primary treatment of the prostate which 
allows potentially higher bowel toxicity that would be acceptable from treatment to a metastatic site. Therefore, the AAPM-101 constraints are retained for pelvic treatments in general [16], with the addition of the ureteric constraints as used in the BR001 trial of SABR for multiple metastases [36]. The PACE study dose constraints are included separately for interest [12]. More recently, prospective data from North America has provided further insight into rectal tolerances in SABR, including the impact of patient-related factors $[37,38]$. These data also relate to the primary treatment of the prostate, and so may not be appropriate in other, nonradical settings. Optimal constraints on the skin are included based on AAPM-101 values [16].

\section{Discussion}

This document presents the current UK consensus on OAR constraints for the delivery of SABR. These are largely based on the constraints reported in the AAPM-101 report from 2010 [16], with modification based on newer data and/or current clinical trial protocols, which, in turn, have also been shaped by more recent data. While many of these constraints have already been adopted in clinical practice with low rates of severe toxicity, it must be remembered that the total number of patients treated with SABR is relatively low (particularly in the setting of SABR for sites other than peripheral lung cancer), and follow-up data is relatively immature. As such, the constraints presented here are not necessarily definitive but form a unified strategy for going forward. On-going prospective evaluation of treated patients, with documentation of toxicities and dosimetric analysis remain essential for future refinement of constraints as required. The adoption of a consistent set of constraints and fractionation schedules across the UK should facilitate the efficient management of this process.

While it is perhaps considered reassuring to adopt constraints from within a formal report such as that of the AAPM, it is also important to note that the constraints within the AAPM-101 report are not based on extensive clinical outcome data, but represent the constraints published by two centres based on limited clinical experience and even "educated guesswork" 
[16], again underlining the importance of on-going prospective data collection. Any existing constraints, including those presented here, are not definitive but should be considered work in progress. Additional evidence from both UK and international studies, along with suggested constraints from other groups [37-39] may be used to further refine values in the future.

The more traditional OAR constraints for conventionally fractionated radiotherapy produced by Emami et al are quoted with reference to specific toxicity outcomes and the associated magnitudes of risk of those endpoints (e.g TD 5/5 represents a $5 \%$ risk of a specific complication at 5 years) [40]. Quantification of risk is unquestionably helpful in clinical practice, both when evaluating plans and discussing treatments with patients. However, because of the nature by which many of the existing SABR constraints were derived, such clinical end-point data is frequently unavailable. Therefore, in this current report we are not able to accompany many of the clinical endpoints with the magnitude of the risks of those endpoints. A comprehensive review of clinically adopted SABR constraints, together with the numbers of patients experiencing severe toxicity for each different set of constraints, was previously published by Grimm et al in 2011 and forms a highly useful complimentary resource [41]. More recently, an entire volume of Seminars of Radiation Oncology was devoted to the modelling and reporting of normal tissue toxicity for SABR treatments[38]. Different constraints were generated based on a range of large and small volumes, and on both high and low risks of each endpoint. Level of acceptable risk varied depending on the severity of the outcome. For example, chest wall (rib fracture) constraints still correlate with a $50 \%$ or $5 \%$ risk of this complication, but for a critical structure like spinal cord (myelitis) risks of $3 \%$ and $1 \%$ would be more appropriate [42]. The AAPM-101 Stereotactic Body Radiotherapy Working Group required that reported constraints were published in the peer-reviewed literature, while the work presented in Seminars in Radiation Oncology included new data and dose response modelling [42], thus facilitating the presentation of constraints for higher and lower risk situations and risk quantifications for multiple fractionation schedules, albeit with the uncertainties that accompany any modelling process. Despite the different approaches in 
generating constraints to this current report, the constraints presented are not dissimilar, which is reassuring. Both sets of constraints, however, require on-going clinical validation.

A further area of uncertainty in determining SABR organ at risk constraints is the impact of individual patient-related factors, such as previous surgeries, diabetes, smoking, heavy previous exposure to cytotoxic agents or patients at the extremes of age. Incorporation of novel agents either before or after SABR is becoming more common, and will also have a significant effect on toxicity [43]. It is currently unknown how such factors should be incorporated into constraint determination for SABR, although some groups of patients have been identified as being at higher risk of certain complications [37]. Intuitively, more conservative constraints may well be more appropriate in patients who might be considered at increased risk of toxicity, as is already recommended for V20 Gy in patients with poor lung function (general point 9 above), and those with underlying liver cirrhosis [39]. Patient-related factors should therefore also be prospectively recorded, alongside dosimetry and outcomes, to guide future modification of constraints, including the potential integration of patient-specific factors.

It is recognised that longer delivery times are associated with superior biological effectiveness in the setting of head and neck cancer [44]. How treatment delivery duration impacts on outcomes in patients receiving SABR is less well documented. Many linac-based centres deliver SABR using VMAT and FFF, in an effort to keep treatment times short. The delivery of SABR using the Cyberknife results in much longer delivery times than associated with repair mechanisms, however there is little evidence that control rates are any lower with this modality. For future analysis, it would be useful to record treatment duration to allow investigation as to whether this has an impact on outcome.

Importantly, the constraints presented in this document are intended for a first course of SABR to a previously non-irradiated site. For patients who have received previous radiotherapy, the 
uncertainties in re-irradiation normal tissue tolerance are substantial. SABR re-irradiation has, however, been successfully delivered to oligometastases, with encouraging rates of local control and low rates of high grade toxicity in small and heterogeneous series $[45,46]$. Most study to date has been devoted to the re-irradiation tolerance of the spinal cord, but even then, patient numbers are relatively low $[46,47]$. As such, determining SABR re-irradiation constraints is an area for future research and is beyond the scope of this current report.

Going forward in the UK, therefore, the priorities are to use the constraints presented here in clinical practice and trials, together with high quality prospective data collection and dosimetric analysis to guide future modification if necessary. It is hoped that the use of a unified set of constraints and fractionation schedules across the UK will facilitate the efficient and effective validation of these constraints.

\section{Conclusion}

A national agreement on SABR dose constraints has been achieved. It is hoped that this unified approach will facilitate standardised implementation of SABR across the UK and will permit meaningful toxicity comparisons between SABR studies and further refinement of the constraints. Further SABR trials developed in the UK will aim to adopt this consensus.

\section{Acknowledgements}

The national radiotherapy trials QA group (RTTQA) is funded by the National Institute for Health Research (NIHR). 
AT, NVA, FM, MA, VK, FS and KA gratefully acknowledge the support of the Royal Marsden Hospital and the Institute for Cancer Research who work in partnership as a NIHR (UK) Biomedical Research Centre.

MAH is funded by MRC grant MC_PC_12001/1. 


\section{References}

[1] Franks KN, Jain P, Snee MP. Stereotactic ablative body radiotherapy for lung cancer. Clin Oncol (R Coll Radiol). 2015;27(5):280-9.

[2] Henderson DR, Tree AC, van As NJ. Stereotactic body radiotherapy for prostate cancer. Clin Oncol (R Coll Radiol). 2015;27(5):270-9.

[3] Aitken KL, Hawkins MA. Stereotactic body radiotherapy for liver metastases. Clin Oncol (R Coll Radiol). 2015;27(5):307-15.

[4] Bhattacharya IS, Hoskin PJ. Stereotactic body radiotherapy for spinal and bone metastases. Clin Oncol (R Coll Radiol). 2015;27(5):298-306.

[5] Hanna GG, Landau D. Stereotactic body radiotherapy for oligometastatic disease. Clin Oncol (R Coll Radiol). 2015;27(5):290-7.

[6] Tree AC, Khoo VS, Eeles RA, et al. Stereotactic body radiotherapy for oligometastases. Lancet Oncol. 2013;14(1):e28-37.

[7] Aitken K, Tree A, Thomas K, et al. Initial UK Experience of Stereotactic Body Radiotherapy for Extracranial Oligometastases: Can We Change the Therapeutic Paradigm? Clin Oncol (R Coll Radiol). 2015;27(7):411-9.

[8] Jain P, Baker A, Distefano G, Scott AJ, Webster GJ, Hatton MQ. Stereotactic ablative radiotherapy in the UK: current status and developments. Br J Radiol. 2013;86(1029):20130331.

[9] Distefano G, Baker A, Scott AJ, Webster GJ, Group USCQA. Survey of stereotactic ablative body radiotherapy in the UK by the QA group on behalf of the UK SABR Consortium. Br J Radiol. 2014;87(1037):20130681.

[10] Conventional Care Versus Radioablation (Stereotactic Body Radiotherapy) for Extracranial Oligometastases (CORE). Clinical Trials. [Accessed 14.12.16]; Available from: https://clinicaltrials.gov/ct2/show/NCT02759783.

[11] Stereotactic Ablative Radiotherapy for Oligometastatic Non-small Cell Lung Cancer (SARON). Clinical Trials. [Accessed: 06.07.16]; Available from: https://clinicaltrials.gov/ct2/show/NCT02417662

[12] Prostate Advances in Comparative Evidence (PACE). Clinical Trials. [Accessed: 06.07.16]; Available from: https://clinicaltrials.gov/ct2/show/NCT01584258.

[13] ABC-07 Addition of stereotactic body radiotherapy to systemic chemotherapy in locally advanced biliary tract. Cancer Research UK. [Accessed: 06.01.16]; Available from:

http://www.cancerresearchuk.org/about-cancer/find-a-clinical-trial/a-trial-looking-chemotherapystereotactic-radiotherapy-people-locally-advanced-bile-duct-cancer-abc-07 - undefined.

[14] Commissioning through Evaluation. [Accessed: 06.07.16]; Available from: https://www.england.nhs.uk/commissioning/spec-services/npc-crg/comm-eval/.

[15] Timmerman RD. An overview of hypofractionation and introduction to this issue of seminars in radiation oncology. Semin Radiat Oncol. 2008;18(4):215-22.

[16] Benedict SH, Yenice KM, Followill D, et al. Stereotactic body radiation therapy: the report of AAPM Task Group 101. Med Phys. 2010;37(8):4078-101.

[17] Lo SS, Sahgal A, Chang EL, et al. Serious complications associated with stereotactic ablative radiotherapy and strategies to mitigate the risk. Clin Oncol (R Coll Radiol). 2013;25(6):378-87.

[18] UK SABR Consortium Guidelines (v5.1 January 2016). [Accessed: 06.07.16]; Available from: http://www.actionradiotherapy.org/wpcontent/uploads/2014/12/UKSABRConsortiumGuidellinesv5.pdf.

[19] Radiotherapy Therapy Oncology Group Contouring Atlases. [Accessed: 06.07.16]; Available from: https://www.rtog.org/CoreLab/ContouringAtlases.aspx

[20] Hiniker SM, Modlin LA, Choi CY, et al. Dose-Response Modeling of the Visual Pathway Tolerance to Single-Fraction and Hypofractionated Stereotactic Radiosurgery. Semin Radiat Oncol. 2016;26(2):97-104.

[21] Grimm J, Sahgal A, Soltys SG, et al. Estimated Risk Level of Unified Stereotactic Body Radiation Therapy Dose Tolerance Limits for Spinal Cord. Semin Radiat Oncol. 2016;26(2):165-71. 
[22] Tamura M, Carron R, Yomo $S$, et al. Hearing preservation after gamma knife radiosurgery for vestibular schwannomas presenting with high-level hearing. Neurosurgery. 2009;64(2):289-96; discussion 96.

[23] ROSEL: A randomized clinical trial of radiosurgery (stereotactic radiotherapy) or surgery in patients with stage IA non- small cell lung cancer who are fit to undergo primary resection.

[Accessed: 14.12.16]; Available from: https://www.vumc.nl/afdelingenthemas/26080/8716235/Roselprotocol.pdf.

[24] Adebahr S, Collette S, Shash E, et al. LungTech, an EORTC Phase II trial of stereotactic body radiotherapy for centrally located lung tumours: a clinical perspective. $\mathrm{Br} J$ Radiol. 2015;88(1051):20150036.

[25] Haasbeek CJ, Lagerwaard FJ, Slotman BJ, Senan S. Outcomes of stereotactic ablative radiotherapy for centrally located early-stage lung cancer. J Thorac Oncol. 2011;6(12):2036-43.

[26] RTOG 0813 Protocol. Seamless Phase I/II Study of Stereotactic Lung Radiotherapy (SBRT) for Early Stage, Centrally Located, Non-Small Cell Lung Cancer (NSCLC) in Medically Inoperable Patients. [Accessed: 14.12.16]; Available from:

https://www.rtog.org/ClinicalTrials/ProtocolTable/StudyDetails.aspx?study=0813.

[27] Nuyttens JJ, van der Voort van Zyp NC, Praag J, et al. Outcome of four-dimensional stereotactic radiotherapy for centrally located lung tumors. Radiother Oncol. 2012;102(3):383-7.

[28] Chaudhuri AA, Tang C, Binkley MS, et al. Stereotacticr ablative radiotherapy (SABR) for treatment of centrla and ultra-central lung tunours. Lung Cancer. 2015;89(1):50-56.

[29] A trial looking at stereotactic body radiotherapy before surgery for pancreatic cancer (SPARC). Cancer Research UK. [Accessed: 14.12.16]; Available from:

http://www.cancerresearchuk.org/about-cancer/find-a-clinical-trial/a-trial-looking-at-stereotacticbody-radiotherapy-before-surgery-for-pancreatic-cancer-sparc - undefined.

[30] Bujold A, Massey CA, Kim JJ, et al. Sequential phase I and II trials of stereotactic body radiotherapy for locally advanced hepatocellular carcinoma. J Clin Oncol. 2013;31(13):1631-9.

[31] Scorsetti M, Comito T, Tozzi A, et al. Final results of a phase II trial for stereotactic body radiation therapy for patients with inoperable liver metastases from colorectal cancer. J Cancer Res Clin Oncol. 2015;141(3):543-53.

[32] Herman JM, Chang DT, Goodman KA, et al. Phase 2 multi-institutional trial evaluating gemcitabine and stereotactic body radiotherapy for patients with locally advanced unresectable pancreatic adenocarcinoma. Cancer. 2015;121(7):1128-37.

[33] Wulf J, Hadinger U, Oppitz U, Thiele W, Ness-Dourdoumas R, Flentje M. Stereotactic radiotherapy of targets in the lung and liver. Strahlenther Onkol. 2001;177(12):645-55.

[34] Wulf J, Guckenberger M, Haedinger U, et al. Stereotactic radiotherapy of primary liver cancer and hepatic metastases. Acta Oncol. 2006;45(7):838-47.

[35] Rusthoven KE, Kavanagh BD, Cardenes $\mathrm{H}$, et al. Multi-institutional phase $\mathrm{I} / \mathrm{II}$ trial of stereotactic body radiation therapy for liver metastases. J Clin Oncol. 2009;27(10):1572-8.

[36] NRG-BR001. A Phase 1 Study of Stereotactic Body Radiotherapy (SBRT) for the Treatment of Multiple Metastases. [Accessed 14.12.16]; Available from:

https://www.rtog.org/ClinicalTrials/ProtocolTable/StudyDetails.aspx?study=1311.

[37] Musunuru HB, Davidson M, Cheung P, Vesprini D, Liu S, Chung H, Chu W, Mamedov A, Ravi A, D'Alimonte L, Commisso K. Predictive parameters of symptomatic hematochezia following 5fraction gantry-based SABR in prostate cancer. International Journal of Radiation Oncology* Biology* Physics. 2016 Apr 1;94(5):1043-51.

[38] Kim DN, Cho LC, Straka C, Christie A, Lotan Y, Pistenmaa D, Kavanagh BD, Nanda A, Kueplian $\mathrm{P}$, Brindle J, Cooley S. Predictors of rectal tolerance observed in a dose-escalated phase 1-2 trial of stereotactic body radiation therapy for prostate cancer. International Journal of Radiation Oncology* Biology* Physics. 2014 Jul 1;89(3):509-17.

[39] Pollom EL, Chin A, Diehn M, Loo BW, Chang DT. Normal tissue constraints for abdominal and thoracic SBRT. Seminars in Radiation Oncology. 2017 Feb 20;27:197-208.

[40] Emami B, Lyman J, Brown A, et al. Tolerance of normal tissue to therapeutic irradiation. Int J Radiat Oncol Biol Phys. 1991;21(1):109-22. 
[41] Grimm J, LaCouture T, Croce R, Yeo I, Zhu Y, Xue J. Dose tolerance limits and dose volume histogram evaluation for stereotactic body radiotherapy. J Appl Clin Med Phys. 2011;12(2):3368.

[42] Grimm J. Dose Tolerance for Stereotactic Body Radiation Therapy. Semin Radiat Oncol. 2016;26(2):87-8.

[43] Kroeze SG, Fritz C, Hoyer M, et al. Toxicity of concurrent stereotactic radiotherapy and targeted therapies or immunotherapy: a systematic review. Cancer Treat Rev. 2017;53:25-37.

[44] Qi XS, Yang Q, Lee SP, Allen Li X, Wang D. An Estimation of Radiobiological Parameters for Head-and-Neck Cancer Cells and the Clinical Implications. Cancers (Basel). 2012;4(2):566-580.

[45] Abusaris $\mathrm{H}$, Hoogeman M, Nuyttens JJ. Re-irradiation: outcome, cumulative dose and toxicity in patients retreated with stereotactic radiotherapy in the abdominal or pelvic region. Technology in cancer research \& treatment. 2012 Dec;11(6):591-7.

[46] Mantel F, Flentje M, Guckenberger M. Stereotactic body radiation therapy in the reirradiation situation-a review. Radiation Oncology. 2013 Jan 5;8(1):7.

[47] Sahgal A, Ma L, Weinberg V, Gibbs IC, Chao S, Chang UK, Werner-Wasik M, Angelov L, Chang EL, Sohn MJ, Soltys SG. Reirradiation human spinal cord tolerance for stereotactic body radiotherapy. International Journal of Radiation Oncology* Biology* Physics. 2012 Jan 1;82(1):10716. 


\section{Figures:}

\begin{tabular}{|c|c|c|}
\hline Organ type & $\begin{array}{c}\text { Principle of Dose Constraint } \\
\text { Descriptor }\end{array}$ & Example \\
\hline Serial & $\begin{array}{l}\text { Dose constraints are typically described } \\
\text { as a threshold dose or higher that can be } \\
\text { given to a small volume of the organ } \\
\text { which receives the highest doses, but the } \\
\text { remaining volume must be spared below } \\
\text { the threshold dose. } \\
\text { (N.B. For cumulative dose-volume } \\
\text { histograms, this is equivalent to the } \\
\text { maximum volume of the organ that can } \\
\text { receive a threshold dose or higher). }\end{array}$ & $\begin{array}{l}\text { The minimum dose to the } 5 \mathrm{cc} \\
\text { volume of small bowel receiving } \\
\text { the highest dose should be lower } \\
\text { than } 25.2 \mathrm{~Gy}(\mathrm{D} 5 \mathrm{cc}<25.2 \mathrm{~Gy} \text { ). } \\
\text { (equivalent to } \mathrm{V} 25.2 \mathrm{~Gy}<5 \mathrm{cc} \text { ) }\end{array}$ \\
\hline $\begin{array}{l}\text { Parallel (Entire organ) } \\
\text { (.e.g. liver, kidneys and } \\
\text { lungs) }\end{array}$ & $\begin{array}{c}\text { Dose constraints are typically described } \\
\text { as a maximum percentage volume of the } \\
\text { organ that can receive a threshold dose } \\
\text { or higher. }\end{array}$ & $\begin{array}{l}\text { The volume of lung receiving a } \\
\text { dose of } 20 \mathrm{~Gy} \text { or higher should be } \\
\text { less than } 10 \% \text { of the total lung } \\
\text { volume (V20Gy<10\%). }\end{array}$ \\
\hline $\begin{array}{c}\text { Parallel (Minimum } \\
\text { critical volume of an } \\
\text { organ) } \\
\text { (.e.g. liver, kidneys and } \\
\text { lungs) }\end{array}$ & $\begin{array}{l}\text { For these, the constraint is typically } \\
\text { described as a minimum critical volume } \\
\text { of the organ which must be spared from } \\
\text { receiving a threshold dose (or higher). }\end{array}$ & $\begin{array}{l}\text { At least } 200 \mathrm{cc} \text { of kidney should } \\
\text { receive a dose of } 16 \mathrm{~Gy} \text { or lower } \\
\text { (Dose to } \geq 200 \mathrm{cc} \leq 16 \mathrm{~Gy} \text { ). }\end{array}$ \\
\hline
\end{tabular}

Figure 1: Description of dose constraint types. 
Table 1: CNS dose constraints

\begin{tabular}{|c|c|c|c|c|c|c|c|c|c|c|c|}
\hline \multirow[b]{2}{*}{ Description } & \multirow[b]{2}{*}{ 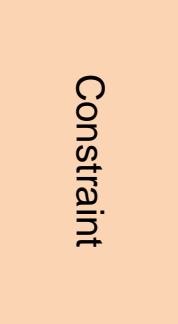 } & \multicolumn{2}{|c|}{1 Fraction } & \multicolumn{2}{|c|}{3 Fractions } & \multicolumn{2}{|c|}{5 Fractions } & \multicolumn{2}{|c|}{8 Fractions } & \multirow[t]{2}{*}{ Source } & \multirow{2}{*}{$\begin{array}{l}\text { Endpoint } \\
\text { (and magnitude of risk if } \\
\text { previously quantified) }\end{array}$} \\
\hline & & 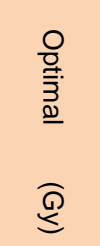 & 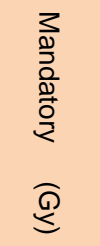 & 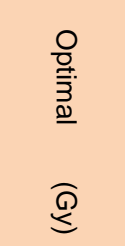 & 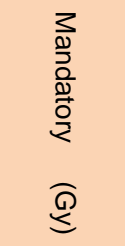 & 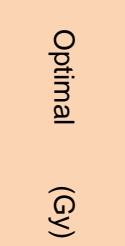 & 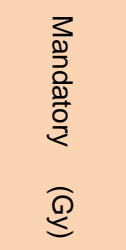 & 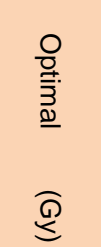 & 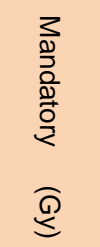 & & \\
\hline $\begin{array}{c}\text { Optic } \\
\text { pathway }\end{array}$ & $\begin{array}{c}\text { DMax }(0.1 \\
\mathrm{cc})\end{array}$ & - & $<8$ & - & $<15$ & - & $<22.5$ & - & - & $\begin{array}{l}\text { AAPM[16]/ } \\
\text { Hiniker[20] }\end{array}$ & $\begin{array}{l}\text { AAPM: Grade } 3+\text { optic neuritis. } \\
\text { Hiniker: } 3 \text { fraction: } 0.8 \% \text { and } 5 \\
\text { fraction: } 1.6 \% \text { risk grade } 4 \text { radiation- } \\
\text { induced optic neuropathy when } \\
\text { limited to } 0.05 \mathrm{cc}\end{array}$ \\
\hline Cochlea & Mean & $<4$ & $<9$ & - & $<17.1$ & - & $<25$ & - & - & $\begin{array}{l}\text { AAPM[16]/ } \\
\text { Tamaru[22] }\end{array}$ & AAPM: Grade 3+ hearing loss \\
\hline $\begin{array}{c}\text { Brainstem } \\
\text { (not medulla) }\end{array}$ & $\begin{array}{c}\text { DMax }(0.1 \\
\mathrm{cc})\end{array}$ & $<10$ & $<15$ & $<18$ & $<23.1$ & $<23$ & $<31$ & - & - & AAPM[16] & Grade 3+ cranial neuropathy \\
\hline \multirow[t]{2}{*}{$\begin{array}{l}\text { Spinal } \\
\text { canal* (inc. }^{*} \\
\text { medulla) }\end{array}$} & $\begin{array}{c}\text { DMax }(0.1 \\
\mathrm{Cc})\end{array}$ & $<10$ & $<14$ & $<18$ & $<21.9$ & $<23$ & $<30$ & $<25$ & $<32$ & $\begin{array}{c}\text { AAPM[16]/ } \\
\text { Grimm[21]/ UK } \\
\text { SABR Consortium } \\
\text { [18]/ } \\
\text { LungTECH[24] } \\
\end{array}$ & $\begin{array}{c}\text { AAPM: Grade } 3+\text { myelitis. Grimm: } \\
\text { single and 3\# optimal doses to } \\
0.1 \text { cc limit risk of grade } 2-4 \\
\text { myelopathy to } \leq 0.4 \%\end{array}$ \\
\hline & $\mathrm{D} 1 \mathrm{cc}$ & $<7$ & - & $<12.3$ & - & $<14.5$ & - & - & & & AAPM: Grade 3+ myelitis \\
\hline $\begin{array}{l}\text { Cauda } \\
\text { equina }\end{array}$ & $\begin{array}{c}\text { DMax }(0.1 \\
\mathrm{cc})\end{array}$ & - & $<16$ & - & $<24$ & - & $<32$ & - & - & AAPM[16] & \multirow[t]{2}{*}{ Grade 3+ neuritis } \\
\hline $\begin{array}{l}\text { \& sacral } \\
\text { plexus }\end{array}$ & D5 cc & - & $<14$ & - & $<22$ & - & $<30$ & - & - & AAPM[16] & \\
\hline \multirow{2}{*}{$\begin{array}{c}\text { Normal } \\
\text { Brain } \\
\text { (Whole } \\
\text { Brain - GTV) }\end{array}$} & $\mathrm{D} 10 \mathrm{cc}$ & $<12$ & - & - & - & - & - & - & - & Group Consensus & Radiation necrosis \\
\hline & D50\% & $<5$ & - & - & - & - & - & - & - & Group Consensus & Cognitive deterioration \\
\hline Lens & $\begin{array}{c}\text { DMax }(0.1 \\
\mathrm{cc})\end{array}$ & $<1.5$ & - & - & - & - & - & - & - & Group Consensus & Cataract formation \\
\hline
\end{tabular}




\begin{tabular}{|c|c|c|c|c|c|c|c|c|c|c|}
\hline Orbit & $\begin{array}{c}\text { DMax }(0.1 \\
\text { Cc) }\end{array}$ & $<8$ & - & - & - & - & - & - & - & Group Consensus \\
\hline
\end{tabular}

*For treatments of the spine itself, these constraints should be applied to the cord PRV.

DMax is the near-point maximum dose, defined in this case as D0.1cc, which is the minimum dose to the $0.1 \mathrm{cc}$ volume of the organ receiving the highest doses.

$\mathrm{D} 1 \mathrm{cc}, \mathrm{D} 5 \mathrm{cc}$ and D10cc are the minimum doses to the specified volume of the organ (1cc, $5 \mathrm{cc}, 10 \mathrm{cc})$ that receive the highest doses.

$\mathrm{D} 50 \%$ is the median dose to the volume (equal to the minimum dose to the $50 \%$ of the volume receiving the highest doses). 
Table 2: Thoracic dose constraints

\begin{tabular}{|c|c|c|c|c|c|c|c|c|c|}
\hline \multirow[b]{2}{*}{ Description } & \multirow{2}{*}{ 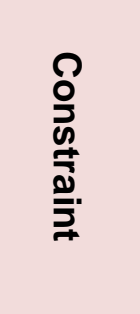 } & \multicolumn{2}{|c|}{3 Fractions } & \multicolumn{2}{|c|}{5 Fractions } & \multicolumn{2}{|c|}{8 Fractions } & \multirow[b]{2}{*}{ Source } & \multirow{2}{*}{$\begin{array}{l}\text { Endpoint } \\
\text { (and } \\
\text { magnitude } \\
\text { of risk } \\
\text { where } \\
\text { quantified) }\end{array}$} \\
\hline & & 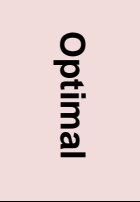 & 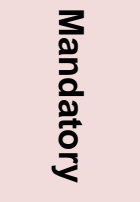 & 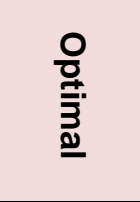 & 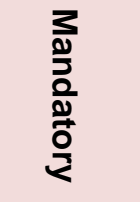 & 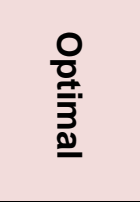 & $\begin{array}{l}\frac{3}{2} \\
\frac{3}{2} \\
\frac{2}{2} \\
\frac{0}{2}\end{array}$ & & \\
\hline $\begin{array}{l}\text { Brachial } \\
\text { Plexus }\end{array}$ & $\begin{array}{l}\text { DMax } \\
(0.5 \mathrm{cc})\end{array}$ & $<24 G y$ & $<26 G y$ & $<27$ Gy & $<29$ Gy & $<27 G y$ & $<38 G y$ & $\begin{array}{c}3 \text { and } 5 \text { fractions plus Optimal constraints } \\
\text { for } 8 \text { fractions: UK SABR Consortium[18]. } \\
8 \text { fractions Mandatory constraints from } \\
\text { LungTECH trial[24] (excluding heart and } \\
\text { great vessels) }\end{array}$ & $\begin{array}{l}\text { Grade 3+ } \\
\text { neuropathy }\end{array}$ \\
\hline Heart & $\begin{array}{l}\text { DMax } \\
(0.5 \mathrm{cc})\end{array}$ & $<24 G y$ & $<26 G y$ & $<27$ Gy & $<29 G y$ & $<50$ Gy & $<60$ Gy & $\begin{array}{l}\text { As above. (8 fraction heart constraints } \\
\text { from UK SABR Consortium[18]) }\end{array}$ & $\begin{array}{l}\text { Grade } 3+ \\
\text { pericarditis }\end{array}$ \\
\hline $\begin{array}{l}\text { Trachea and } \\
\text { bronchus }\end{array}$ & $\begin{array}{l}\text { DMax } \\
(0.5 \mathrm{cc})\end{array}$ & $<30 G y$ & $<32 G y$ & $<32 G y$ & $<35 G y$ & $<32 G y$ & $<44 G y$ & As above & $\begin{array}{l}\text { Grade 3+ } \\
\text { stenosis/ } \\
\text { fistula }\end{array}$ \\
\hline $\begin{array}{l}\text { Normal } \\
\text { Lungs* } \\
\text { (Lungs-GTV) }\end{array}$ & V20 Gy & - & $<10 \%$ & - & $<10 \%$ & - & $<10 \%$ & As above & $\begin{array}{l}\text { Grade 3+ } \\
\text { pneumonitis }\end{array}$ \\
\hline \multirow{2}{*}{$\begin{array}{l}\text { Chest } \\
\text { Wall }\end{array}$} & $\begin{array}{l}\text { DMax } \\
(0.5 \mathrm{cc})\end{array}$ & $<37$ Gy & - & $<39 G y$ & - & $<39$ Gy & - & As above & \multirow{2}{*}{$\begin{array}{l}\text { Grade 3+ } \\
\text { fracture or } \\
\text { pain }\end{array}$} \\
\hline & $\mathrm{D} 30 \mathrm{cc}$ & $<30 \mathrm{~Gy}$ & - & $<32 \mathrm{~Gy}$ & - & $<35 G y$ & - & As above & \\
\hline Great Vessels & $\begin{array}{l}\text { DMax } \\
(0.5 \mathrm{cc})\end{array}$ & - & $<45 G y$ & - & < 53Gy & - & - & $\begin{array}{c}\text { As above (8 fractions great vessels } \\
\text { constraints from UK SABR } \\
\text { Consortium[18]) }\end{array}$ & $\begin{array}{l}\text { Grade 3+ } \\
\text { aneurysm }\end{array}$ \\
\hline
\end{tabular}


*Normal Lung (Lungs-GTV) constraints for the treatment of two or three lung lesions in the same patient should follow the guidelines in general point 9 above. DMax is the near-point maximum dose, defined in this case as D0.5cc, which is the minimum dose to the $0.5 \mathrm{cc}$ volume of the organ receiving the highest doses. V20 Gy is the percentage volume of the organ receiving a dose of 20Gy or higher.

$\mathrm{D} 30 \mathrm{cc}$ is the minimum dose to the $30 \mathrm{cc}$ of the organ that receives the highest doses. 
Table 3: Gastro-intestinal dose constraints

\begin{tabular}{|c|c|c|c|c|c|c|c|}
\hline \multirow{2}{*}{ Description } & \multirow{2}{*}{ Constraint } & \multicolumn{2}{|c|}{3 fractions } & \multicolumn{2}{|c|}{5 fractions } & \multirow{2}{*}{ Source } & \multirow{2}{*}{ End point } \\
\hline & & Optimal & Mandatory & Optimal & Mandatory & & \\
\hline \multirow{5}{*}{ Duodenum } & DMax $(0.5 \mathrm{cc})$ & - & $<22.2 \mathrm{~Gy}$ & - & $<35 G y$ & \multirow{5}{*}{$\begin{array}{l}3 \text { fraction: AAPM[16] } \\
5 \text { fraction: ABC-07[13]/ } \\
\text { SPARC protocols[28] }\end{array}$} & \multirow[t]{5}{*}{ Grade 3+ ulceration } \\
\hline & $\mathrm{D} 1 \mathrm{cc}$ & - & - & $<33 G y$ & - & & \\
\hline & D5 cc & - & $<16.5 \mathrm{~Gy}$ & $<25 G y$ & - & & \\
\hline & $\mathrm{D} 9 \mathrm{cc}$ & - & - & $<15 \mathrm{~Gy}$ & - & & \\
\hline & $\mathrm{D} 10 \mathrm{cc}$ & - & $<11.4 \mathrm{~Gy}$ & - & $<25 G y$ & & \\
\hline \multirow{4}{*}{ Stomach } & DMax $(0.5 \mathrm{cc})$ & - & $<22.2 \mathrm{~Gy}$ & $<33 G y$ & $<35 G y$ & \multirow{4}{*}{ As above } & \multirow{4}{*}{$\begin{array}{l}\text { Grade 3+ } \\
\text { ulceration/ } \\
\text { fistulation }\end{array}$} \\
\hline & D5 cc & - & - & $<25 G y$ & - & & \\
\hline & $\mathrm{D} 10 \mathrm{cc}$ & - & $<16.5 \mathrm{~Gy}$ & - & $<25 G y$ & & \\
\hline & D50 cc & - & - & $<12 G y$ & - & & \\
\hline \multirow{3}{*}{$\begin{array}{l}\text { Small } \\
\text { Bowel }\end{array}$} & $\mathrm{DMax}(0.5 \mathrm{cc})$ & - & $<25.2 \mathrm{~Gy}$ & $<30 G y$ & $<35 \mathrm{~Gy}$ & \multirow{3}{*}{ As above } & \multirow{3}{*}{$\begin{array}{l}\text { Grade 3+ } \\
\text { enteritis/ } \\
\text { obstruction }\end{array}$} \\
\hline & D5 cc & - & $<17.7 \mathrm{~Gy}$ & $<25 G y$ & - & & \\
\hline & D10 cc & - & - & - & $<25 G y$ & & \\
\hline $\begin{array}{l}\text { Common } \\
\text { Bile Duct }\end{array}$ & DMax (0.5 cc) & $<50$ Gy & - & $<50$ Gy & - & As above & \\
\hline Oesophagus & DMax $(0.5 \mathrm{cc})$ & - & $<25.2 \mathrm{~Gy}$ & $<32 G y$ & $\begin{array}{c}<34 \mathrm{~Gy}(<40 \\
\text { Gy for } 8 \\
\text { fractions }) \\
\end{array}$ & $\begin{array}{l}\text { As above plus LungTECH } \\
\text { for } 8 \text { fraction schedules[24] }\end{array}$ & $\begin{array}{l}\text { Grade } 3+\text { stenosis/ } \\
\text { fistula }\end{array}$ \\
\hline Large Bowel & DMax (0.5 cc) & - & $<28.2 \mathrm{~Gy}$ & - & $<32 \mathrm{~Gy}$ & As above & Grade 3+ colitis/ fistula \\
\hline
\end{tabular}




\begin{tabular}{|c|c|c|c|c|c|c|c|}
\hline Rectum & $\operatorname{DMax}(0.5 \mathrm{cc})$ & - & $<28.2 \mathrm{~Gy}$ & - & $<32 G y$ & AAPM[16] & Grade 3+ colitis/ fistula \\
\hline \multicolumn{8}{|c|}{ Parallel GI organs } \\
\hline Normal Liver & V10 Gy & - & - & $<70 \%$ & - & $\begin{array}{c}3 \text { fraction: AAPM[16]/ Wulf } \\
\text { et al[32,33]/ Rusthoven et } \\
\text { al [34] }\end{array}$ & $\begin{array}{l}\text { Grade } 3+\text { liver function } \\
\text { dysfunction/ }\end{array}$ \\
\hline \multirow[t]{3}{*}{$\begin{array}{l}\text { (Liver minus } \\
\text { GTV) }\end{array}$} & Mean dose & - & - & $<13 G y$ & $<15.2 \mathrm{~Gy}$ & \multirow[t]{3}{*}{$\begin{array}{l}5 \text { fraction: ABC-07[13]/ } \\
\text { SPARC [28] protocols }\end{array}$} & \multirow[t]{3}{*}{$\begin{array}{l}\text { radiation-induced liver } \\
\text { disease (classic or non- } \\
\text { classic) }\end{array}$} \\
\hline & D50\% & $<15 \mathrm{~Gy}$ & - & - & - & & \\
\hline & $\begin{array}{c}\text { Dose to } \geq 700 \\
\text { Cc }\end{array}$ & $<15 G y$ & $<19.2 \mathrm{~Gy}$ & - & - & & \\
\hline \multirow[t]{2}{*}{$\begin{array}{c}\text { Kidneys } \\
\text { (individual } \\
\text { and } \\
\text { combined) }\end{array}$} & Mean dose & - & - & $<10 \mathrm{~Gy}$ & - & \multirow[t]{2}{*}{$\begin{array}{l}3 \text { fraction: AAPM[16] } \\
5 \text { fraction: ABC-07[13]/ } \\
\text { SPARC [28]protocols }\end{array}$} & \multirow[t]{3}{*}{$\begin{array}{l}\text { Grade } 3+\text { renal function } \\
\text { dysfunction }\end{array}$} \\
\hline & $\begin{array}{c}\text { Dose to } \geq 200 \\
\mathrm{Cc}^{\star}\end{array}$ & - & $<16 G y$ & - & - & & \\
\hline $\begin{array}{l}\text { If solitary } \\
\text { kidney or if } \\
\text { one kidney } \\
\text { mean dose } \\
>10 \text { Gy }\end{array}$ & V10 Gy & - & - & $<10 \%$ & $<45 \%$ & $\begin{array}{c}\text { ABC-07[13]/ SPARC[28] } \\
\text { protocols }\end{array}$ & \\
\hline
\end{tabular}

*If total kidney volume $<200 \mathrm{cc}$, or treating renal or adrenal lesions, then total dose to contralateral kidney should be $<16 \mathrm{~Gy}$ and aim to minimise spillage into ipsilateral kidney if possible.

DMax is the near-point maximum dose, defined in this case as D0.5cc, which is the minimum dose to the $0.5 c c$ volume of the organ receiving the highest doses. $\mathrm{D} 1 \mathrm{cc}, \mathrm{D} 5 \mathrm{cc}, \mathrm{D} 9 \mathrm{cc}, \mathrm{D} 10 \mathrm{cc}$ and D50 cc are the minimum doses to the specified volume of the organ (1cc, 5cc, etc.) that receive the highest doses. $\mathrm{V} 10 \mathrm{~Gy}$ is the percentage volume of the organ receiving a dose of 10Gy or higher.

Dose to $\geq 700 \mathrm{cc}$ and $\geq 200 \mathrm{cc}$ is the maximum dose to the specified volume of the organ $(700 \mathrm{cc}, 200 \mathrm{cc})$ that receives the lowest doses. 
Tables 4a, b and c: Pelvic and other tissues dose constraints

Table 4a: Pelvic dose constraints (for non-prostate primary irradiation)

\begin{tabular}{|c|c|c|c|c|c|c|c|}
\hline \multirow[b]{2}{*}{ Description } & \multirow[b]{2}{*}{ Constraint } & \multicolumn{2}{|c|}{3 Fractions } & \multicolumn{2}{|c|}{5 Fractions } & \multirow[b]{2}{*}{ Source } & \multirow[b]{2}{*}{ Endpoint } \\
\hline & & 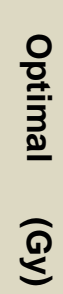 & 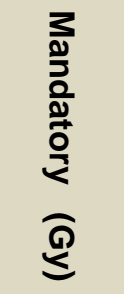 & 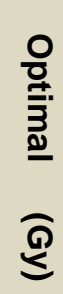 & 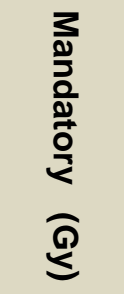 & & \\
\hline \multirow[t]{2}{*}{ Bladder } & D15 cc & - & $<16.8$ & - & $<18.3$ & \multirow{2}{*}{$\begin{array}{c}\text { AAPM } \\
{[16]} \\
\end{array}$} & \multirow{2}{*}{$\begin{array}{c}\text { Grade } 3+\text { cystitis } \\
\text { / fistula }\end{array}$} \\
\hline & DMax $(0.5 \mathrm{cc})$ & - & $<28.2$ & - & $<38$ & & \\
\hline \multirow[t]{2}{*}{ Penile Bulb } & D3 cc & - & $<21.9$ & - & $<30$ & \multirow{2}{*}{$\begin{array}{c}\text { AAPM } \\
{[16]}\end{array}$} & \multirow{2}{*}{$\begin{array}{l}\text { Grade 3+ } \\
\text { impotence }\end{array}$} \\
\hline & DMax $(0.5 \mathrm{cc})$ & - & $<42$ & - & $<50$ & & \\
\hline Ureter & DMax $(0.5 c c)$ & - & $<40$ & - & $<45$ & BR001[35] & \\
\hline
\end{tabular}

DMax is the near-point maximum dose, defined in this case as D0.5cc, which is the minimum dose to the $0.5 \mathrm{cc}$ volume of the organ receiving the highest doses. $\mathrm{D} 3 \mathrm{cc}$ and D15 cc are the minimum doses to the specified volume of the organ $(3 \mathrm{cc}, 15 \mathrm{cc})$ that receive the highest doses. 
Table 4b: Other tissues dose constraints

\begin{tabular}{|c|c|c|c|c|c|}
\hline \multirow[t]{2}{*}{ Description } & \multirow[t]{2}{*}{ Constraint } & 3 fractions & 5 fractions & \multirow[t]{2}{*}{ Source } & \multirow[t]{2}{*}{ Endpoint } \\
\hline & & Optimal (Gy) & Optimal (Gy) & & \\
\hline \multirow[t]{2}{*}{ Skin } & $\begin{array}{c}\text { DMax (0.5 } \\
\text { cc) }\end{array}$ & $<33$ & $<39.5$ & \multirow[t]{2}{*}{ AAPM[16] } & \multirow{2}{*}{$\begin{array}{l}\text { Grade 3+ } \\
\text { ulceration }\end{array}$} \\
\hline & $\mathrm{D} 10 \mathrm{cc}$ & $<30$ & $<36.5$ & & \\
\hline $\begin{array}{c}\text { Femoral } \\
\text { Head }\end{array}$ & $\mathrm{D} 10 \mathrm{cc}$ & $<21.9$ & $<30$ & AAPM[16] & Grade 3+ necrosis \\
\hline
\end{tabular}

DMax is the near-point maximum dose, defined in this case as D0.5cc, which is the minimum dose to the $0.5 \mathrm{cc}$ volume of the organ receiving the highest doses. $\mathrm{D} 10 \mathrm{cc}$ is the minimum dose to the $10 \mathrm{cc}$ of the organ that receive the highest doses.

Table 4c: PACE trial[12] constraints for primary prostate radiotherapy only

\begin{tabular}{|c|c|c|c|c|}
\hline \multirow[b]{2}{*}{ Description } & \multirow{2}{*}{$\begin{array}{c}\text { Constraint } \\
\text { (Prostate primary only) }\end{array}$} & \multicolumn{2}{|c|}{$\begin{array}{ll}5 & \text { Fractions }\end{array}$} & \multirow[b]{2}{*}{ Source } \\
\hline & & Optimal & Mandatory & \\
\hline \multirow{3}{*}{ Rectum } & D50\% & - & $<18.1 \mathrm{~Gy}$ & \multirow{3}{*}{ PACE trial[12] } \\
\hline & D20\% & - & $<29 G y$ & \\
\hline & D1 cc & - & $<36 G y$ & \\
\hline \multirow[t]{2}{*}{ Bladder } & D40\% & - & $<18.1 \mathrm{~Gy}$ & \multirow[t]{2}{*}{ As above } \\
\hline & V37 Gy & $<5 \mathrm{cc}$ & $<10 \mathrm{cc}$ & \\
\hline Prostatic urethra (if visible) & D50\% & $<42 \mathrm{~Gy}$ & - & As above \\
\hline Femoral head & D5\% & - & $<14.5 \mathrm{~Gy}$ & As above \\
\hline Penile Bulb & D50\% & - & $<29.5 \mathrm{~Gy}$ & As above \\
\hline Testicles & Avoid beam & entry e.g. & Blocking structure & As above \\
\hline \multirow[t]{2}{*}{ Bowel } & D5 cc & - & $<18.1 \mathrm{~Gy}$ & \multirow[t]{2}{*}{ As above } \\
\hline & D1 cc & - & $<30 G y$ & \\
\hline
\end{tabular}

